\title{
Energy Consumption in China's Construction Industry: Energy Driving and Driven Abilities from a Regional Perspective
}

\author{
Jingxin GAO \\ School of Economics and Management, Dalian University of Technology, Dalian 116024, China \\ Yunong CHEN \\ Institute of Environmental Science, Leiden University, 2300 RA Leiden, The Netherlands \\ E-mail: yunong2017chen@163.com \\ Xiaoyang ZHONG \\ Institute of Environmental Science, Leiden University, 2300 RA Leiden, The Netherlands \\ E-mail: x.zhong@cml.leidenuniv.nl \\ Xianrui MA \\ School of Economics and Management, Southwest University, Chongqing 400700, China; School of \\ Management Science and Real Estate, Chongqing University, Chongqing 400044, China \\ E-mail: maxianrui@swu.edu.cn
}

\begin{abstract}
The construction industry is one of the largest energy consumers in China. It not only uses energy directly but also consumes a large amount of embodied energy hidden in intermediate goods and services from other industries. This paper utilizes the multi-regional input-output (MRIO) model to measure the embodied energy consumption in China's construction industry at the province level. To quantify the backward and forward linkages between the construction industry and other industries, the energy-driven and energy-driving abilities of the construction industry are investigated for 30 provinces. The results show that the values of the energy-driven coefficients are significantly larger than the energy-driving coefficients, indicating that the construction industry is highly dependent on products from other industries and other regions, not vice versa. The construction industries in the southwest and northwest regions of China have the highest energy-driven coefficients, showing that the construction industries in west China heavily rely on indirect energy embodied in goods and services. This particularly applies in Guangxi and Hainan provinces, which have the highest energydriven abilities and the lowest energy-driving abilities. The findings can facilitate the policy-makers to examine the critical energy-saving paths.
\end{abstract}

Keywords construction industry; multi-regional input-output (MRIO); energy-driven ability; energydriving ability

Received May 21, 2019, accepted November 11, 2019

Supported by General Projects of Talent Introduction Project in 2020 of Dalian University of Technology (DUT20RC(3)061); National Natural Science Foundation of China (71801024); National Key R\&D Program of China (2018YFD1100203) 


\section{Introduction}

China is currently in a rapid urbanization stage led by the $60 \%$ urbanization rate target as a part of the 13 th Five-Year Plan released by the central government ${ }^{[1]}$. As a result, the number and the scale of China's cities are continually increasing, leading to significant growth in construction activities. Since the construction industry is a typical energy-intensive industry, the rapid urbanization process stimulates a large amount of energy consumption and carbon emissions, placing much stress on the environment and the economy ${ }^{[2,3]}$. Generally, in comparison with direct energy consumption by the construction activities, more energy is consumed through the utilization of intermediate goods and service in the upstream supply chain, which is referred to as embodied energy ${ }^{[4-6]}$. Liu, et al. also pointed out that embodied energy consumption is dramatically larger than the direct energy consumption in the construction industry ${ }^{[7]}$.

Most previous studies focused on direct energy consumption of on-site production activities in the construction industry, neglecting the embodied energy consumed in the entire industrial chain $^{[8-12]}$. Some recent investigations explored the embodied energy consumption at multiple scales, based on various lifecycle assessment tools ${ }^{[13,14]}$. For example, Lin, et al. studied the embodied energy of the construction industry in China by using the single region inputoutput (SRIO) model ${ }^{[15]}$. Dixit and Singh investigated the embodied energy consumption of five higher education buildings based on IO-based hybrid $(\mathrm{IOH})$ model ${ }^{[16,17]}$. Han, et al. measured the embodied energy for building construction engineering based on the bill of quantities (BOQs) ${ }^{[18]}$. Biswas provided life-cycle embodied energy analysis using a life-cycle assessment (LCA) methodology ${ }^{[19]}$. However, although embodied energy consumption in the construction industry has been widely investigated in these studies, insufficient insights have been provided into the energy flows through interregional trade from the industrial and multiregional perspectives. The SRIO model, the BOQ, and the process-based LCA all fail to examine the concealed relationships along the economic network and inter-regional energy flows. It is important to account for distinct regional characteristics to track crucial disparities and linkages.

Recent developments in multi-region input-output (MRIO) models can facilitate the assessment of inter-regional embodied energy flows. The MRIO model can reflect economic interactions and regional characteristics and has been applied extensively. For example, embodied energy use and carbon emissions within a target country have been quantified based on MRIO models $^{[20-24]}$. Another strand of research uses the MRIO model to explore the energy consumption embodied in the international trade along the global energy networks ${ }^{[25-29]}$. However, only a few national investigations have considered the interregional flows of energy resources between diverse industries. For example, Liang, et al. applied the MRIO model and scenario analysis to investigate the energy requirements in eight economic regions in China ${ }^{[30]}$. Meng, et al. analyzed the growth trend and spatial distribution of $\mathrm{CO}_{2}$ emissions and pointed out that emission transfer distorted regional emissions and the intensities ${ }^{[31]}$. Guo, et al. analyzed the carbon emissions from a provincial perspective, indicating that the eastern provinces had larger $\mathrm{CO}_{2}$ emissions resulted from their international trade. Other studies have explored China's regional and sectoral GHG emission patterns ${ }^{[32-35]}$ and their driving forces ${ }^{[36]}$, carbon emissions embodied in trade ${ }^{[37]}$, as well as the energy consumption and carbon print of specific buildings ${ }^{[38]}$. 
Although these studies have considered embodied energy and the energy flows from the interregional and industrial perspective, only a few of them have explored the embodied energy and energy flows in the construction industry, the most energy-intensive industry. Hong, et al. have studied the embodied energy consumption in construction industry from the perspective of inter-regional trade of China's construction industry ${ }^{[39,40]}$. The embodied energy accounting and resource-dependent geographical distribution are completed from a quantitative point of view. However, due to the large gap between the geographical area, industry scale, population, and economic level of each region, it is unreasonable to compare the quantity of direct energy consumption without considering the regional disparities and temporal differences.

To fill these gaps in the literature, this study evaluates the embodied energy consumption in the construction industry from an inter-regional perspective based on the MRIO model. After that, the energy-driving and energy-driven abilities in the construction industry are examined over the entire industrial chain to show the backward linkages and forward linkages between the construction industry and other industries. To do this, a model of energy-driving and energy-driven coefficients is established.

The rest of the paper is organized as follows. Section 2 provides the methodology for identifying the energy-driving and energy-driven abilities in the construction industry. In Section 3, the data sources and processing are described. Section 4 demonstrates the empirical results. In Section 5, the findings are further discussed. Section 6 provides conclusions and recommendations.

\section{Methodology}

In this study, the direct energy consumption of the construction industry refers to the energy consumed by on-site construction activities. The embodied energy consumption covers not only the energy consumed by on-site construction activities but also the energy consumed by upstream energy consumption activities that support the on-site activities. To reflect the real and complete energy consumption levels of the construction industries in 30 regions, their energy-driving and energy-driven abilities are explored. The framework of this study is shown in Figure 1.

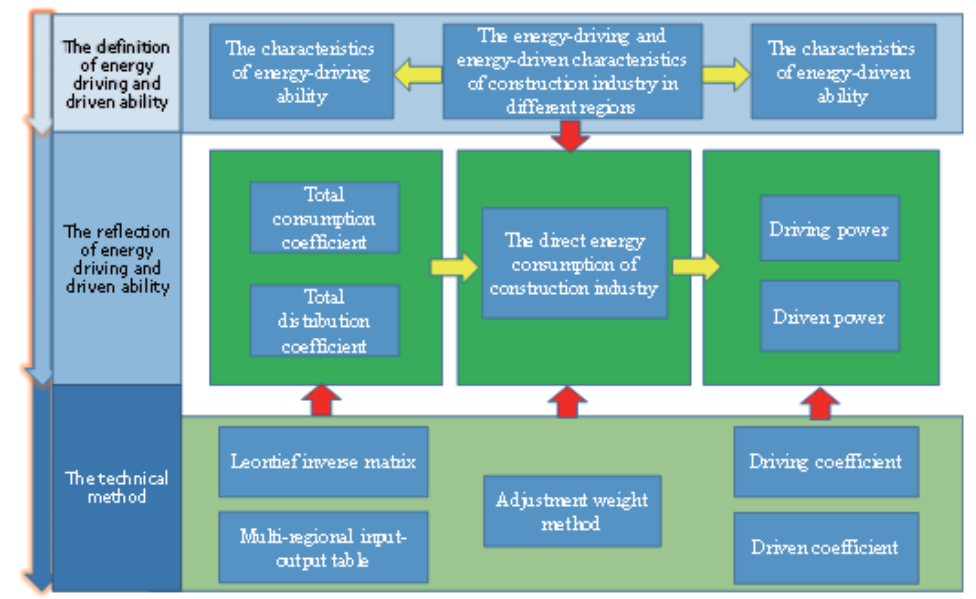

Figure 1 The research framework 


\subsection{The Definitions of Energy-Driving and Energy-Driven Abilities}

The total energy-consumption coefficient of the industry $i$ is the amount of energy consumed by industry $i$ to produces per unit goods or services; the total energy-distribution coefficient of the industry $i$ is the amount of energy distributed to other industries when the industry $i$ produces per unit goods or services ${ }^{[41]}$. The total energy-consumption coefficient represents the backward linkages so it is used to measure the energy-driven abilities of a certain industry. The total energy-distribution coefficient reflects the forward linkages and can be used to measure the energy-driving abilities ${ }^{[42]}$. However, the total energy-consumption and energy-distribution coefficient cannot represent these two influential abilities of the construction industry on the entire industrial system. Therefore, this paper employed the energy sensitivity coefficient and energy influence coefficient to reveal the construction industry's energy-driven and energydriving ability on the entire industrial chain.

\subsection{The Measurement of Energy-Driven Ability}

The energy-driven ability is measured by the sensitivity coefficient, which is calculated based on the total energy-consumption coefficient. The fundamental equation of the MRIO model is detailed as follows ${ }^{[43]}$.

$$
\begin{aligned}
& B=(I-A)^{-1} F \\
& B=\left[\begin{array}{c}
B^{1} \\
B^{2} \\
\vdots \\
B^{n}
\end{array}\right], \quad A=\left[\begin{array}{cccc}
A^{11} & A^{12} & \cdots & A^{1 n} \\
A^{21} & A^{22} & \cdots & A^{2 n} \\
\vdots & \vdots & \ddots & \vdots \\
A^{n 1} & A^{n 2} & \cdots & A^{n n}
\end{array}\right], \quad F=\left[\begin{array}{cccc}
f^{11} & f^{12} & \cdots & f^{1 n} \\
f^{21} & f^{22} & \cdots & f^{2 n} \\
\vdots & \vdots & \ddots & \vdots \\
f^{n 1} & f^{n 2} & \cdots & f^{n n}
\end{array}\right] .
\end{aligned}
$$

$B$ is the total output vector. $B_{l}^{S}$ represents the total output of industry 1 in region $s . I$ is the same order identity matrix. $(I-A)^{-1}$ is the Leontief inverse matrix. The technical coefficient sub-matrix $A^{r s}=\left(a_{i j}^{r s}\right)$ is given by $a_{i j}^{r s}=z_{i j}^{r s} / x_{j}^{s} \cdot z_{i j}^{r s}$ is the monetary flows from industry $i$ in region $r$ to industry $j$ in region $s . x_{j}^{s}$ is the total output of industry $j$ in region s. $F=\left(f_{i}^{r s}\right)$ is the final demand matrix. $f_{i}^{r s}$ is the final demand for the industry $i$ in region $s$ from region $r$.

To calculate the energy embodied in goods and services, the energy intensity $(E)$ needs to be computed as follows:

$$
E=e_{i}^{r} / X_{i}^{r}
$$

where $e_{i}^{r}$ is the energy consumption of industry $i$ in region $r$. $X_{i}^{r}$ is the total output of industry $i$ in region $r$. The total energy-consumption coefficient (TEC) can be obtained as follows:

$$
\mathrm{TEC}=E(I-A)^{-1} F .
$$

Based on the concept of sensitivity coefficient, the energy-driven coefficient $F_{j}$ is shown in Equation (5).

$$
F_{j}=\frac{\frac{1}{n} \sum_{i=1}^{n} \operatorname{tec}_{i j}}{\frac{1}{n^{2}} \sum \sum \operatorname{tec}_{i j}}=\frac{\sum_{i=1}^{n} \operatorname{tec}_{i j}}{\frac{1}{n} \sum \sum \operatorname{tec}_{i j}}, \quad j=1,2, \cdots, n .
$$


In Equation (5), $F_{j}$ is the energy-driven coefficient of industry $j$, which reflects the energydriven ability on the whole industrial system. tec ${ }_{i j}$ is the total energy-consumption coefficient. If $F_{j}>1$, the energy-driven ability of industry $j$ is over the average level of the energy-driven abilities of all industries.

\subsection{The Measurement of Energy-Driving Ability}

The energy-driving ability is measured by the influence coefficient, which is calculated based on the total energy-distribution coefficient. The structure is symmetrical between the total energy-distribution coefficient and the total energy-consumption coefficient ${ }^{[44-47]}$. The total energy-distribution coefficient (TDC) can be obtained as follows.

$$
\begin{aligned}
& \mathrm{TDC}=E(I-C)^{-1} F \\
& C=\left[\begin{array}{cccc}
C^{11} & C^{12} & \cdots & C^{1 n} \\
C^{21} & C^{22} & \cdots & C^{2 n} \\
\vdots & \vdots & \ddots & \vdots \\
C^{n 1} & C^{n 2} & \cdots & C^{n n}
\end{array}\right], \quad F=\left[\begin{array}{cccc}
f^{11} & f^{12} & \cdots & f^{1 n} \\
f^{21} & f^{22} & \cdots & f^{2 n} \\
\vdots & \vdots & \ddots & \vdots \\
f^{n 1} & f^{n 2} & \cdots & f^{n n}
\end{array}\right],
\end{aligned}
$$

where the technical coefficient sub-matrix $C^{r s}=\left(c_{i j}^{r s}\right)$ is given by $c_{i j}^{r s}=z_{i j}^{r s} / y_{i}^{s} . \quad z_{i j}^{r s}$ is the monetary flows from industry $i$ in region $r$ to industry $j$ in region $s . y_{j}^{s}$ is the total input of industry $j$ in region s. $F=\left(f_{i}^{r s}\right)$ is the final demand matrix. $f_{i}^{r s}$ is the final demand for industry $i$ in region $s$ from region $r$.

$D$ is the total energy-distribution coefficient matrix. The energy-driving coefficient $F_{i}$ can be calculated as follows:

$$
F_{i}=\frac{\frac{1}{n} \sum_{j=1}^{n} \operatorname{tdc}_{i j}}{\frac{1}{n^{2}} \sum \sum \operatorname{tdc}_{i j}}=\frac{\sum_{j=1}^{n} \operatorname{tdc}_{i j}}{\frac{1}{n} \sum \sum \operatorname{tdc}_{i j}}, \quad j=1,2, \cdots, n .
$$

In Equation (8), $F_{i}$ is the energy-driving coefficient of industry $i$, which reflects the energydriving ability on the whole industrial system. $\operatorname{tdc}_{i j}$ is the total energy-distribution coefficient. If $F_{i}>1$, the energy-driving ability of industry $i$ is larger than the average level of the energydriving abilities of all industries.

\section{Data Sources and Processing}

\subsection{Multi-Regional Input-Output Table}

In this study, the total consumption and total distribution coefficient are calculated based on the MRIO table which is derived from the China Emissions Accounts \& Datasets (CEAD). The MRIO table in 2012 is the most up-to-date table covering 30 separate economic sectors in 30 provinces and municipalities ${ }^{[48,49]}$. The relevant industries and their codes are listed in the datasets of CEAD and Appendix A.

\subsection{The Construction Industry Impact on Energy Consumption of 30 Industries in 30 Regions}

The raw data for energy consumption in this study comes from the China Energy Statistical Yearbook Tables of 30 Regions in China, China's Statistic Yearbook, and China's Regional 
Statistic Yearbook. The energy consumed by primary industries and the tertiary industries can be derived from the statistical yearbook directly. However, the unavailability of direct energy data that specifically matched the secondary industry classifications in the MRIO table was a major obstacle. Moreover, the formation of the data in the regional statistic yearbook for different regions is inconsistent. To obtain the data with the same caliber and specifically matching the industrial classifications in the MRIO tables, this study employs the "adjustment weight method" adopted by $[50,51]$.

First, the energy intensity of the industrial sectors is computed at the national level as shown follows.

$$
\mathrm{AEC}_{i}=\frac{E_{i}}{G_{i}},
$$

where $\mathrm{AEC}_{i}$ and $E_{i}$ are the energy intensity and the energy consumption of sector $i$ at the national level, respectively. $G_{i}$ is the total output of sector $i$ at the national level. The adjustment weight can be calculated as:

$$
\begin{aligned}
& \mathrm{AW}_{j}=\frac{e_{j}}{N G_{j}}, \\
& N=\frac{E}{G} .
\end{aligned}
$$

In Equations (10) and (11), $\mathrm{AW}_{j}$ is the adjustment coefficient for region $i . e_{j}$ is the actual energy consumption of the secondary industry in region $j . N$ is the national energy intensity of the secondary industry. $G_{j}$ is the total output of the secondary industry in region $j . E$ and $G$ are the energy consumption and total output of the secondary industry in the country, respectively.

$$
\mathrm{AEC}_{i j}=\mathrm{AEC}_{i} \times \mathrm{AW}_{j}
$$

$\mathrm{AEC}_{i j}$ is the average energy consumption coefficient of sector $i$ in region $j$. Furthermore, we can get the direct energy consumption of sector $i$ in region $j$ as follows.

$$
E_{i j}=\mathrm{AEC}_{i j} \times G_{i j}
$$

\section{Results}

\subsection{Total Energy-Consumption Coefficient and Energy-Driven Coefficient}

The results of the total energy-consumption and energy-driven coefficients for the construction industry in 30 regions of China are shown in Table 1.

As shown in Table 1, the total energy-consumption coefficient for the construction industry is greater than 1 in 28 provinces. Only the total energy-consumption coefficients of Hubei and Fujian are below 1. In particular, the total energy-consumption coefficient for the construction industry in Guangxi is 17.005, far exceeding the other provinces. Hainan also shows a high total energy-consumption coefficient at 12.5. Among the other areas, the total energy-consumption coefficients of Yunnan and Guizhou are around 6.0 and that of Chongqing is about 3.8. In the other 25 provinces, the total energy-consumption coefficients are all below 3.0. As for the energydriven coefficient of the construction industry, Guangxi has the largest energy-driven ability, with an energy-driven coefficient of more than 6.8 , far exceeding that of the other regions. 
Hainan province is the second-largest influential region, with an energy-driven coefficient of more than 1.1. The energy-driven coefficients for the construction industries in Yunnan and Guizhou are larger than 0.5. For other 26 regions, all energy-driven coefficients are below 0.35 .

Table 1 Total energy-consumption and energy-driven coefficients in the construction industry

\begin{tabular}{llllll}
\hline Region & $\begin{array}{l}\text { Total energy- } \\
\text { consumption } \\
\text { coefficient }\end{array}$ & $\begin{array}{l}\text { Energy-driven } \\
\text { coefficient }\end{array}$ & Region & $\begin{array}{l}\text { Total energy- } \\
\text { consumption } \\
\text { coefficient }\end{array}$ & $\begin{array}{l}\text { Energy-driven } \\
\text { coefficient }\end{array}$ \\
\hline Beijing & 1.465 & 0.130 & Henan & 1.293 & 0.115 \\
Tianjin & 1.417 & 0.126 & Hubei & 0.982 & 0.087 \\
Hebei & 1.986 & 0.176 & Hunan & 2.045 & 0.182 \\
Shanxi & 2.142 & 0.190 & Guangdong & 1.870 & 0.166 \\
Inner Mongolia & 1.002 & 0.089 & Guangxi & 17.005 & 6.836 \\
Liaoning & 1.739 & 0.154 & Hainan & 12.509 & 1.110 \\
Jilin & 1.704 & 0.151 & Chongqing & 3.892 & 0.345 \\
Heilongjiang & 1.649 & 0.146 & Sichuan & 1.590 & 0.141 \\
Shanghai & 1.567 & 0.139 & Guizhou & 5.895 & 0.523 \\
Jiangsu & 1.490 & 0.132 & Yunnan & 6.021 & 0.534 \\
Zhejiang & 1.410 & 0.125 & Shaanxi & 2.435 & 0.216 \\
Anhui & 1.984 & 0.176 & Gansu & 2.482 & 0.220 \\
Fujian & 0.848 & 0.075 & Qinghai & 2.804 & 0.249 \\
Jiangxi & 1.689 & 0.150 & Ningxia & 2.687 & 0.239 \\
Shandong & 1.386 & 0.123 & Xinjiang & 2.737 & 0.243 \\
\hline
\end{tabular}

Note: Tons of standard coal equivalent $/ 10^{4} \mathrm{RMB}$.

\subsection{Total Energy-Distribution Coefficient and Energy-Driving Coefficient}

The results of the total energy-distribution coefficients and the energy-driving coefficients for the construction industry in 30 regions are listed in Table 2.

Compared with the total energy-consumption coefficients, the total energy-distribution coefficients for the regional construction industries are significantly lower. There are three provinces, Hubei, Shanxi, and Guizhou, where the total energy-distribution coefficients are over 0.1. Among the other provinces, 28 of the 30 have a total energy-distribution coefficient below 0.1. Guangxi is the only province with a total energy-distribution coefficient below 0.03 . Similarly, the energy-driving coefficient of Hubei is the highest. The energy-driving coefficients in Shanxi, Shandong, Guangdong, Guizhou, Inner Mongolia, Ningxia, Tianjin, Hebei, Hunan, and Sichuan are greater than 0.01. Except for the construction industries in these regions, the energy-driving coefficients of the construction industries in the other 19 regions are less than 0.01. In particular, the energy-driving coefficients in Guangxi and Hainan are the smallest among all 30 regions at 0.002 and 0.004 , respectively. 
Table 2 Total energy-distribution and energy-driving coefficients in the construction industry

\begin{tabular}{llllll}
\hline Region & $\begin{array}{l}\text { Total energy- } \\
\text { distribution } \\
\text { coefficient }\end{array}$ & $\begin{array}{l}\text { Energy- } \\
\text { driven } \\
\text { coefficient }\end{array}$ & Region & $\begin{array}{l}\text { Total energy- } \\
\text { distribution } \\
\text { coefficient }\end{array}$ & $\begin{array}{l}\text { Energy- } \\
\text { driving } \\
\text { coefficient }\end{array}$ \\
\hline Beijing & 0.064 & 0.008 & Henan & 0.047 & 0.006 \\
Tianjin & 0.082 & 0.010 & Hubei & 0.131 & 0.016 \\
Hebei & 0.082 & 0.010 & Hunan & 0.082 & 0.010 \\
Shanxi & 0.112 & 0.013 & Guangdong & 0.096 & 0.012 \\
Inner Mongolia & 0.093 & 0.011 & Guangxi & 0.016 & 0.002 \\
Liaoning & 0.054 & 0.007 & Hainan & 0.034 & 0.004 \\
Jilin & 0.044 & 0.005 & Chongqing & 0.066 & 0.008 \\
Heilongjiang & 0.035 & 0.004 & Sichuan & 0.085 & 0.010 \\
Shanghai & 0.064 & 0.008 & Guizhou & 0.100 & 0.012 \\
Jiangsu & 0.037 & 0.004 & Yunnan & 0.059 & 0.007 \\
Zhejiang & 0.055 & 0.007 & Shaanxi & 0.056 & 0.007 \\
Anhui & 0.041 & 0.005 & Gansu & 0.064 & 0.008 \\
Fujian & 0.050 & 0.006 & Qinghai & 0.072 & 0.009 \\
Jiangxi & 0.031 & 0.004 & Ningxia & 0.088 & 0.011 \\
Shandong & 0.098 & 0.012 & Xinjiang & 0.059 & 0.007 \\
\hline
\end{tabular}

Note: Tons of standard coal equivalent $/ 10^{4} \mathrm{RMB}$.

\subsection{Direct Energy Consumption in the Construction Industry in 30 Regions}

The detailed information of direct energy consumption in the construction industry of 30 regions is listed in Table 3 .

Table 3 shows that direct energy consumption in 20 provinces is larger than 1.50 Mtce. The construction industry in Guangdong is the highest energy consumer with 7.1546 Mtce energy resources used in one year. The region with the second-highest value is Shandong province, where the construction industry consumed 6.38 Mtce in 2012. The energy consumed by the construction industries in Zhejiang and Sichuan ranks third and fifth, with energy consumption amounts to 4.37 Mtce and 4.19 Mtce, respectively. The construction industries of Hebei, Hunan, Inner Mongolia, Hubei, and Jiangsu are important energy consumers with consumption between 3.50 Mtce and 4 Mtce in 2012. By contrast, the energy consumption in the construction industries in Guangxi, Qinghai, and Hainan did not reach 0.50 Mtce in 2012. 
Table 3 Direct energy consumption in the construction industry in 30 regions

\begin{tabular}{llll}
\hline Region & Energy (Mtce) & Region & Energy (Mtce) \\
\hline Beijing & 1.5045 & Henan & 1.6994 \\
Tianjin & 2.1918 & Hubei & 3.56 \\
Hebei & 3.9699 & Hunan & 3.7217 \\
Shanxi & 1.6368 & Guangdong & 7.1546 \\
Inner Mongolia & 3.5691 & Guangxi & 0.4550 \\
Liaoning & 2.2364 & Hainan & 0.3098 \\
Jilin & 0.9744 & Chongqing & 2.5059 \\
Heilongjiang & 0.5460 & Sichuan & 4.19 \\
Shanghai & 2.1475 & Guizhou & 0.85 \\
Jiangsu & 3.5574 & Yunnan & 1.8956 \\
Zhejiang & 4.3693 & Shaanxi & 1.9450 \\
Anhui & 1.5506 & Gansu & 0.9988 \\
Fujian & 2.0828 & Qinghai & 0.3707 \\
Jiangxi & 0.7479 & Ningxia & 0.7437 \\
Shandong & 6.3800 & Xinjiang & 0.9802 \\
\hline
\end{tabular}

\section{Discussion}

\subsection{Comparison of Energy-Driving and Energy-Driven Coefficients}

To assess the relationship and difference between the energy-driving coefficients and energydriven coefficients in the 30 regions, charts displaying the trends in the energy-driven coefficients and energy-driving coefficients were drawn with the energy-driven coefficients sorted in descending order. The details are shown in Figure 2.

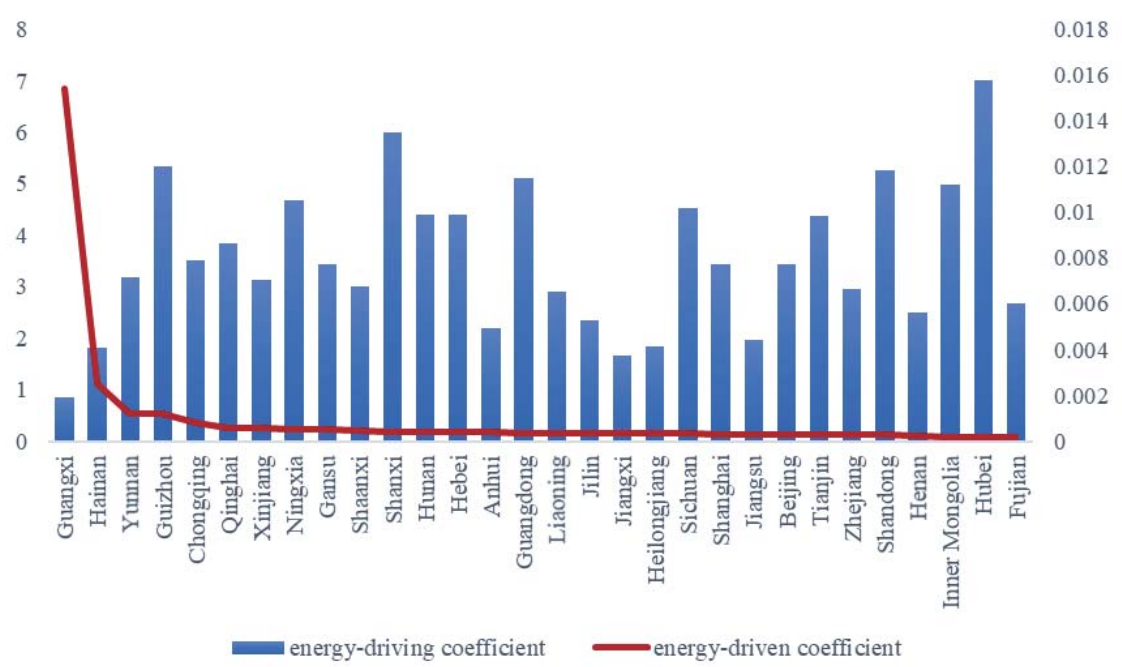

Figure 2 The trends of the energy-driven and energy-driving coefficients in 30 regions 
Figure 2 shows that there is no obvious correlation between the energy-driving coefficients and the energy-driven coefficients in the construction industries of these 30 regions. When the energy-driven coefficients decrease, the energy-driving coefficients show irregular fluctuations. Notably, the energy-driven coefficients in the construction industries in Guangxi and Hainan are the highest while their energy-driving coefficients are the lowest, which indicates that the construction industries in these regions have the most significant energy-driven impact and the least energy-driving impact on the entire industrial system.

More importantly, the values of the energy-driven coefficients in the 30 regions are far larger than the energy-driving coefficients in the construction industries, which shows the construction industry highly depends on intermediate products from other industries and other regions, not vice versa.

\subsection{Spatial Analysis of Energy-Driven Abilities in 30 Regions}

According to the total energy-consumption coefficients and energy-driven coefficients, these 30 provinces were classified into 7 groups, including the southwest region (1), the northwest region (2), the second eastern coastal areas (3), the northeast region (4), the northeast-southeastsouthwest triangular (5), the eastern coastal areas (6), and others (7). The detailed information of geographic distribution are shown in Table 4.

Regions of group (1) are mainly in the southwest of China. This group includes Guangxi, Hainan, Yunnan, Guizhou, and Chongqing, where the total energy-consumption coefficients and energy-driven coefficients are the highest. Regions of group (2) are located in the northwest region of China, including Qinghai, Xinjiang, and Ningxia, where the total energy-consumption coefficients and energy-driven coefficients are the second highest. The third group, including Hunan, Hebei, Anhui, and Guangdong, is called the second eastern coastal area since it is juxtaposed with group (6). Group (6) includes provinces located in the eastern coastal areas. They have the second-lowest total energy-consumption coefficients and energy-driven coefficients. Liaoning and Jilin are provinces included in group (4), the northeast region of China, with the fourth-highest total energy-consumption coefficients and energy-driven coefficients. The fifth group includes Jiangxi, Heilongjiang, and Sichuan, located in the northeast, southwest, and northwest of China. The three provinces form the three vertices of the triangle. Therefore, group (5) is called the northeast-southeast-southwest triangular. The other provinces are classified into the last group, with the lowest total energy-consumption coefficients and energy-driven coefficients. The detailed information for each group is shown in Table 4.

Table 4 shows that the construction industries in the southwest region of China are most energy-intensive, using the largest amount of indirect energy embodied in goods and services from other sectors. Similarly, the construction industries in the northwest region of China are also significantly energy-intensive than other regions, inducing a lot of indirect energy production to support their own development. By contrast, the construction industries in the eastern coastal areas and Henan, Inner Mongolia, Hubei, and Fujian have the lowest total energy-consumption coefficients and energy-driven coefficients, indicating that the construction industries in these regions consume less embodied energy compared with other regions. 
Table 4 The provinces classification according to energy-driven abilities

\begin{tabular}{llc}
\hline Group & Province & $\begin{array}{c}\text { Energy-driven } \\
\text { coefficient }\end{array}$ \\
\hline 1 (Southwest region) & $\begin{array}{l}\text { Guangxi, Hainan, Yunnan, Guizhou, } \\
\text { Chongqing }\end{array}$ & $0.345-6.836$ \\
2 (Northwest Region) & $\begin{array}{l}\text { Qinghai, Xinjiang, Ningxia, Gansu, } \\
\text { Shaanxi, Shanxi }\end{array}$ & $0.190-0.249$ \\
3 (The second Eastern coastal ar- & Hunan, Hebei, Anhui, Guangdong & $0.166-0.182$ \\
eas) & Liaoning, Jilin & $0.151-0.154$ \\
4 (Northeast region) & Jiangxi, Heilongjiang, Sichuan & $0.141-0.150$ \\
5 (Northeast-Southeast-Southwest & & \\
6 triangular) & Shanghai, Jiangsu, Beijing, Tianjin, & $0.123-0.139$ \\
7 (Others) & Zhejiang, Shandong & \\
\hline
\end{tabular}

\subsection{Spatial Analysis of the Energy-Driving Abilities in 30 Regions}

According to the total energy-distribution coefficients and energy-driving coefficients, the 30 provinces were classified into 8 groups. Hubei is the only province classified into group 1 with the highest energy-driving ability in the construction industry. The second group includes Shanxi, Guizhou, Shandong, and Guangdong, with total energy-distribution coefficients ranging from 0.096 to 0.112 and energy-driving coefficients ranging from 0.012 to 0.013 . Inner Mongolia, Ningxia, Sichuan, Hunan, Hebei, and Tianjin constitute group (3). Three municipalities, i.e., Beijing, Shanghai, Chongqing, and Qinghai and Gansu are classified into group (4). Yunnan, Xinjiang, Shaanxi, Zhejiang, and Liaoning, constitute the group (5). Group (6) includes Fujian, Henan, Jilin, and Anhui. Jiangsu, Heilongjiang, Hainan, and Jiangxi are in group (7). Guangxi is the only province classified in group (8), with the lowest total energy-distribution coefficient and energy-driving coefficient. The details are shown in Table 5.

Table 5 The group classification according to energy-driving abilities

\begin{tabular}{lll}
\hline Group & Province & Energy-driving coefficient \\
\hline 1 & Hubei & 0.016 \\
2 & Shanxi, Guizhou, Shandong, Guangdong & $0.012-0.013$ \\
3 & Inner Mongolia, Ningxia, Sichuan, Hunan, Hebei, Tianjin & $0.010-0.011$ \\
4 & Qinghai, Chongqing, Gansu, Shanghai, Beijing & $0.008-0.009$ \\
5 & Yunnan, Xinjiang, Shaanxi, Zhejiang, Liaoning & $0.007-0.007$ \\
6 & Fujian, Henan, Jilin, Anhui & $0.005-0.006$ \\
7 & Jiangsu, Heilongjiang, Hainan, Jiangxi & $0.004-0.004$ \\
8 & Guangxi & 0.002 \\
\hline
\end{tabular}

As shown in Table 5, the geographic distribution of the provinces with similar energy-driving abilities in the same groups is irregular. There is no obvious relationship between adjacent 
regions. Furthermore, the total energy-distribution coefficients and energy-driving coefficients are relatively small, which further underscores the immobility characteristic of the construction industry's products.

\subsection{Comparison of the Direct Energy Consumption and Energy-Driven Abilities in the Construction Industry}

To highlight the mismatch in the direct energy consumption and energy-driven abilities in the construction industries in the 30 regions, a scatter plot of the energy-driven abilities in the different groups was drawn (see Figure 3).

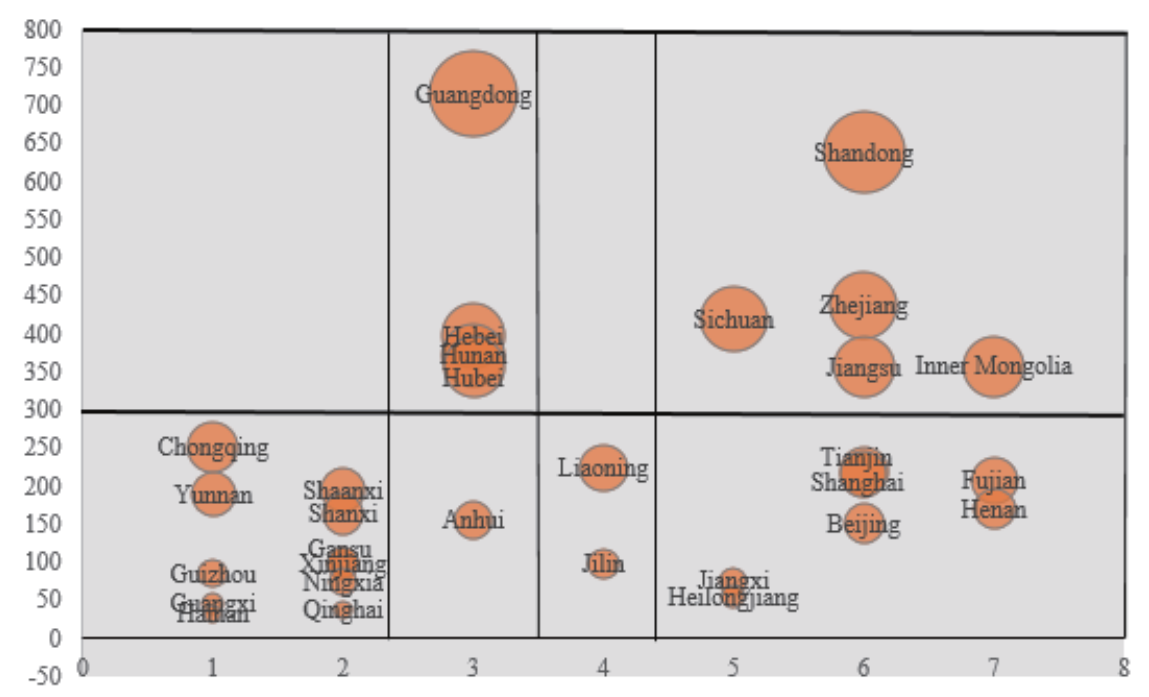

Figure 3 The distribution of energy-driven abilities in 30 regions

According to Figure 3, although the direct energy consumption in groups 1 and 2 are the lowest, the energy-driven abilities of the construction industries in these regions are the most striking. By contrast, the construction industries in Guangdong, Hebei, Hunan, Hubei, Shandong, Zhejiang, and Sichuan consume a great deal of direct energy although they do not cause a significant increase in energy consumption in other industries inside or outside the region. Therefore, different energy-saving strategies should be adopted in regional construction industries. To improve energy-resource structures and customized energy regulation policies, with both energy-driven and energy-driving characteristics considered, is crucial for alleviating the energy crisis and related environmental issues.

\section{Conclusion}

Due to China's rapid urbanization and the associated demand for new construction, more energy and resources are needed to support the entire construction industry value chain. However, there is insufficient information on the embodied energy consumed along the interregional and intersectoral trade network, which may result in unwise or irrational policies. To fill this gap, this paper uses the MRIO model to investigate the embodied energy in China's regional construction industries. The total energy-consumption coefficients and total energy-distribution 
coefficients in different regions are presented to capture the embodied energy consumption, as well as cross-regional energy, flows in the construction industry. Furthermore, the coefficients of energy-driving and energy-driven are calculated to measure the forward and backward impacts of the construction industry on the entire industrial system. The results offer a sound reference and insights into the embodied energy consumption of the construction industry across China. The major findings are as follows:

1) Guangxi had the highest significant energy-driven ability, with an energy-driven coefficient reaching more than 6.8, far exceeding that of other regions. Hainan province was the second-highest region. As for the energy-driving ability, the total energy-distribution coefficients in Hubei, Shanxi, and Guizhou were the highest. The energy-distribution coefficients in other provinces were below 0.1. In particular, Guangxi had the lowest energy-driving ability with the energy-distribution coefficient below 0.03 .

2) Guangxi and Hainan had the highest energy-driven coefficients and the lowest energydriving coefficients. This showed that the construction industries in Guangxi and Hainan use more embodied energy from the goods or services from other industries and regions to support their own construction activities. By contrast, the products and services from the construction industries in Guangxi and Hainan had no significant influence on other industries.

3) The energy-driven coefficients were significantly larger than the energy-driving coefficients in the construction industries of 30 regions. This indicates the unique characteristics of the products and services provided by the construction activities. In general, construction products mainly exist in the form of fixed assets and are unsuitable for long-distance transportation. However, the construction industry is highly depended on intermediate products and services from other industries and regions.

4) The construction industries in the southwest and northwest regions of China are the most embodied energy-intensive and, therefore, induce significant intermediate goods and services produced from other industries. By comparison, the construction industries in eastern coastal areas and Henan, Inner Mongolia, Hubei, and Fujian have the lowest energy-driven coefficients.

The energy-saving and emissions-reduction targets have been the critical tasks in the "13th five-year plan" in China. As the results show, the regional construction industries are important energy consumers and have different energy-driving abilities. It is essential to promote technology-based efficiency improvement of energy consumption in these construction industries, especially in the southwest and northwest regions in China. Energy-saving strategies should not only focus on the reduction of direct energy consumption, but also consider the management of indirect energy flows. The varying forward and backward linkages of the construction industries should be emphasized for differential strategy-making in different regions. Further research is needed to improve specific efficiency promotion pathways as well as to explore the multiregional energy trade patterns considering the backward and forward linkages between the construction industry and other industries.

\section{References}

[1] Guo H, Yuan Y. The optimal regulation of urban-rural income gap, economic growth and urbanization in the 13th Five Year Plan. Exploration of Economic Problems, 2018(6): 101-111. 
[2] Yan J, Zhao T, Kang J. Sensitivity analysis of technology and supply change for $\mathrm{CO}_{2}$ emission intensity of energy-intensive industries based on input-output model. Applied Energy, 2016, 171: 456-467.

[3] Zheng J, Chen W. The coordinated development of the energy-intensive industrial cluster in circular economy. Science \& Technology Progress \& Policy, 2010, 27(2): 53-56.

[4] Hong J, Shen G Q, Guo S, et al. Energy use embodied in China's construction industry: A multi-regional input-output analysis. Renewable \& Sustainable Energy Reviews, 2016, 53: 1303-1312.

[5] Li J S, Xia X H, Chen G Q, et al. Optimal embodied energy abatement strategy for Beijing economy: Based on a three-scale input-output analysis. Renewable \& Sustainable Energy Reviews, 2015, 53: 1602-1610.

[6] Wu X D, Xia X H, Chen G Q, et al. Embodied energy analysis for coal-based power generation systemhighlighting the role of indirect energy cost. Applied Energy, 2016, 184: 936-950.

[7] Liu L, Ma J, Sun P. Analysis on influencing factors of total energy consumption in China's construction industry based on input-output method. Journal of University of Electronic Science and Technology (Social Science Edition), 2015(2): 41-45.

[8] Zhang S X, Zhang D. The energy consumption of construction industry in Shaanxi province and comparing to eastern coastal provinces. Applied Mechanics \& Materials, 2013, 448-453: 4382-4386.

[9] Xue X, Wu H, Zhang X, et al. Measuring energy consumption efficiency of the construction industry: The case of China. Journal of Cleaner Production, 2015, 107: 509-515.

[10] Jia J S, Chen Q, Hu L L. Analysis on the carbon emission (CE) arising from the direct energy consumption (EC) of Beijing's construction industry. Applied Mechanics \& Materials, 2014, 522-524: 1822-1825.

[11] Qi S, Zhang Y, Wang X. Research on direct energy consumption and structure character of carbon emission in Chinese construction industry. Construction Economy, 2012(12): 58-62.

[12] Zeng S, Zhang X, Jorge O J, et al. Relationship between energy consumption and economic development in construction industry. Journal of Engineering Design \& Technology, 2010, 8(3): 257-273.

[13] Dixit M K. Life cycle embodied energy analysis of residential buildings: A review of literature to investigate embodied energy parameters. Renewable and Sustainable Energy Reviews, 2017, 79: 390-413.

[14] Stephan A, Stephan L. Life cycle energy and cost analysis of embodied, operational and user-transport energy reduction measures for residential buildings. Applied Energy, 2016, 161: 445-464.

[15] Lin L, Fan Y, Xu M, et al. A decomposition analysis of embodied energy consumption in China's construction industry. Sustainability, 2017, 9(9): 1583.

[16] Dixit M K, Singh S. Embodied energy analysis of higher education buildings using an input-output-based hybrid method. Energy \& Buildings, 2018, 161: 41-54.

[17] Dixit M K. Embodied energy analysis of building materials: An improved IO-based hybrid method using sectoral disaggregation. Energy, 2017, 124: 46-58.

[18] Han M Y, Chen G Q, Shao L, et al. Embodied energy consumption of building construction engineering: Case study in E-town, Beijing. Energy \& Buildings, 2013, 64(5): 62-72.

[19] Biswas W K. Carbon footprint and embodied energy consumption assessment of building construction works in Western Australia. International Journal of Sustainable Built Environment, 2014, 3(2): 179-186.

[20] Weber C L, Peters G P, Guan D, et al. The contribution of Chinese exports to climate change. Energy Policy, 2008, 36(9): 3572-3577.

[21] Lenzen M, Dey C, Foran B. Energy requirements of Sydney households. Ecological Economics, 2004, 49(3): 375-399.

[22] Mäenpää I, Siikavirta H. Greenhouse gases embodied in the international trade and final consumption of Finland: An input-output analysis. Energy Policy, 2007, 35(1): 128-143.

[23] Mcgregor P G, Swales J K, Turner K. The $\mathrm{CO}_{2}$ 'trade balance' between Scotland and the rest of the UK: Performing a multi-region environmental input-output analysis with limited data. Ecological Economics, 2008, 66(4): 662-673.

[24] Nijdam D S, Wilting H C, Goedkoop M J, et al. Environmental load from Dutch private consumption: How much damage takes place abroad?. Journal of Industrial Ecology, 2010, 9(1-2): 147-168.

[25] Chen Z M, Chen G Q. An overview of energy consumption of the globalized world economy. Energy Policy, 2011, 39(10): 5920-5928.

[26] Chen G Q, Chen Z M. Greenhouse gas emissions and natural resources use by the world economy: Ecological input-output modeling. Ecological Modelling, 2011, 222(14): 2362-2376.

[27] Ahmad N, Wyckoff A. Carbon dioxide emissions embodied in international trade of goods. OECD Science 
Technology \& Industry Working Papers, 2003, 25(4): 1-22.

[28] Berlin P O. GHG emissions in the global supply chain of food products. International Input, 2008.

[29] Nakano S, Okamura A, Sakurai N, et al. The measurement of $\mathrm{CO}_{2}$ embodiments in international trade: Evidence from the harmonised input-output and bilateral trade database. OECD Science Technology \& Industry Working Papers, 2009.

[30] Liang Q M, Fan Y, Wei Y M. Multi-regional input-output model for regional energy requirements and $\mathrm{CO}_{2}$ emissions in China. Energy Policy, 2007, 35(3): 1685-1700.

[31] Meng L, Guo J E, Chai J, et al. China's regional CO emissions: Characteristics, inter-regional transfer and emission reduction policies. Energy Policy, 2011, 39(10): 6136-6144.

[32] Su B, Ang B W. Input-output analysis of $\mathrm{CO}_{2}$ emissions embodied in trade: A multi-region model for China. Ecological Economics, 2014, 114(24): 377-384.

[33] $\mathrm{Su} \mathrm{B}$, Ang $\mathrm{B}$ W. Input-output analysis of $\mathrm{CO}_{2}$ emissions embodied in trade: Competitive versus noncompetitive imports. Energy Policy, 2013, 56(5): 83-87.

[34] Liu L C, Liang Q M, Wang Q. Accounting for China's regional carbon emissions in 2002 and 2007: Production-based versus consumption-based principles. Journal of Cleaner Production, 2015, 103: 384392.

[35] Yuan B, Ren S, Chen X. The effects of urbanization, consumption ratio and consumption structure on residential indirect $\mathrm{CO}_{2}$ emissions in China: A regional comparative analysis. Applied Energy, 2015, 140: 94-106.

[36] Liu Z, Geng Y, Lindner S, et al. Uncovering China's greenhouse gas emission from regional and sectoral perspectives. Energy, 2012, 45(1): 1059-1068.

[37] $\mathrm{Su} \mathrm{B}$, Ang B W. Input-output analysis of $\mathrm{CO}_{2}$ emissions embodied in trade: A multi-region model for China. Ecological Economics, 2014, 114(24): 377-384.

[38] Wang N, Chang Y C, Dauber V. Carbon print studies for the energy conservation regulations of the UK and China. Energy \& Buildings, 2010, 42(5): 695-698.

[39] Hong J, Shen G Q, Guo S, et al. Energy use embodied in China's construction industry: A multi-regional input-output analysis. Renewable \& Sustainable Energy Reviews, 2016, 53: 1303-1312.

[40] Hong J, Shen Q G, Li Z C, et al. An integrated framework for embodied energy quantification of buildings in China: A multi-regional perspective. Resources, Conservation and Recycling, 2018, 138: 183-193.

[41] Mi Z, Meng J, Guan D, et al. Chinese $\mathrm{CO}_{2}$ emission flows have reversed since the global financial crisis. Nature Communications, 2017, 8(1): 1712.

[42] Tang Z, Yan X. Input-occupancy-output analysis of industrial wastewater discharge coefficients and backward and forward linkages: Multi-regional occupancy. Journal of Systems Science \& Complexity, 2015, 28(6): $1344-1362$.

[43] Jingxin G, Xiaoyang Z, Weiguang C, et al. Dilution effect of the building area on energy intensity in urban residential buildings. Nature Communications, 2019, 10(1): 4944.

[44] Mu T, Xia Q, Kang C. Input-output table of electricity demand and its application. Energy, 2010, 35(1): 326-331.

[45] Tarancón M A, Río P D, Albiñana F C. Assessing the influence of manufacturing sectors on electricity demand. A cross-country input-output approach. Energy Policy, 2010, 38(4): 1900-1908.

[46] Suganthi L, Samuel A A. Energy models for demand forecasting — A review. Renewable \& Sustainable Energy Reviews, 2012, 16(2): 1223-1240.

[47] Meng F Y, Zhou D Q, Zhou P, et al. Sectoral comparison of electricity-saving potentials in China: An analysis based on provincial input-output tables. Energy, 2014, 72(7): 772-782.

[48] Mi Z, Meng J, Zheng H, et al. A multi-regional input-output table mapping China's economic outputs and interdependencies in 2012. Scientific Data, 2018, 5: 180155.

[49] Pan W, Pan W, Shi Y, et al. China's inter-regional carbon emissions: An input-output analysis under considering national economic strategy. Journal of Cleaner Production, 2018, 197: 794-803.

[50] Hong J, Zhong X, Guo S, et al. Water-energy nexus and its efficiency in China's construction industry: Evidence from province-level data. Sustainable Cities and Society, 2019, 48: 101557.

[51] Huang Y, Lei Y, Wu S. Virtual water embodied in the export from various provinces of China using multi-regional input-output analysis. Water Policy, 2016, 19(2): 197-215. 
Appendix A Multi-input-output table Department and code

\begin{tabular}{|c|c|c|c|}
\hline Province & Code & Sector & Code \\
\hline Beijing & $\mathrm{A}$ & Agriculture & 1 \\
\hline Tianjin & $\mathrm{B}$ & Coal mining & 2 \\
\hline Hebei & $\mathrm{C}$ & Petroleum and gas & 3 \\
\hline Shanxi & $\mathrm{D}$ & Metal mining & 4 \\
\hline Inner Mongolia & $\mathrm{E}$ & Nonmetal mining & 5 \\
\hline Liaoning & $\mathrm{F}$ & Food processing and tobaccos & 6 \\
\hline Jilin & G & Textile & 7 \\
\hline Heilongjiang & $\mathrm{H}$ & Clothing, leather, fur, etc. & 8 \\
\hline Shanghai & I & Wood processing and furnishing & 9 \\
\hline Jiangsu & $\mathrm{J}$ & Paper making, printing, stationery, etc. & 10 \\
\hline Zhejiang & $\mathrm{K}$ & Petroleum refining, coking, etc. & 11 \\
\hline Anhui & $\mathrm{L}$ & Chemical industry & 12 \\
\hline Fujian & M & Nonmetal products & 13 \\
\hline Jiangxi & $\mathrm{N}$ & Metallurgy & 14 \\
\hline Shandong & $\mathrm{O}$ & Metal products & 15 \\
\hline Henan & $\mathrm{P}$ & General and specialist machinery & 16 \\
\hline Hubei & Q & Transport equipment & 17 \\
\hline Hunan & $\mathrm{R}$ & Electrical equipment & 18 \\
\hline Guangdong & $\mathrm{S}$ & Electronic equipment & 19 \\
\hline Guangxi & $\mathrm{T}$ & Instrument and meter & 20 \\
\hline Hainan & $\mathrm{U}$ & Other manufacturing & 21 \\
\hline Chongqing & $\mathrm{V}$ & Electricity and hot water production and supply & 22 \\
\hline Sichuan & $\mathrm{W}$ & Gas and water production and supply & 23 \\
\hline Guizhou & $\mathrm{X}$ & Construction & 24 \\
\hline Yunnan & $\mathrm{Y}$ & Transport and storage & 25 \\
\hline Shaanxi & $\mathrm{Z}$ & Wholesale and retailing & 26 \\
\hline Gansu & AA & Hotel and restaurant & 27 \\
\hline Qinghai & $\mathrm{AB}$ & Leasing and commercial services & 28 \\
\hline Ningxia & $\mathrm{AC}$ & Scientific research & 29 \\
\hline Xinjiang & $\mathrm{AD}$ & Other services & 30 \\
\hline
\end{tabular}

